\title{
End-of-life modelling of buildings to support more informed decisions towards achieving circular economy targets
}

\author{
Sahar Mirzaie ${ }^{1}$ (D) $\cdot$ Mihaela Thuring $^{2} \cdot$ Karen $^{\text {Allacker }}{ }^{3}$ \\ Received: 23 March 2020 / Accepted: 4 August 2020 / Published online: 15 September 2020 \\ (C) The Author(s) 2020
}

\begin{abstract}
Purpose Life cycle assessment (LCA) is an internationally accepted method to assess the environmental impacts of buildings. A major methodological challenge remains the modelling of the end-of-life stage of buildings and allocation of benefits and burdens between systems. Various approaches are hence applied in practice to date. This paper compares the two methods widely renowned in Europe - the EC product environmental footprint (PEF) method and the CEN standards: EN 15804+A1 and EN15978 - and offers insights about their fitness for achieving circularity goals.

Methods The EC PEF method and the CEN EN 15804/EN 15978 standards were methodologically analysed with a focus on the end-of-life modelling and allocation approach and were applied to a building case study. The EN 15804+A1 standard explains the guidelines but does not offer a modelling formula. Accordingly, this paper proposes a formula for the CEN standards using identical parameters as in the end-of-life circular footprint formula (CFF) of the EC PEF Guidance v6.3 to increase consistency among LCA studies. The calculation formulas were then applied to a newly constructed office building. A comparative analysis of both the implementation and results are described, and recommendations are formulated.

Results In the absence of databases compatible with the two LCA methods and comprising all building products, the Ecoinvent datasets had to be remodelled to enable a comparative modular assessment. This proved to be a laborious process. The EC PEF method and CEN standards showed similar impacts and hotspots for the case study building. The module D in the CEN standards includes a significant share of positive impacts, but due to collective accounting, it does not clearly communicate these benefits. The summation of burdens and benefits in the EC PEF method reduces its transparency, while the allocation and quality factors enable this method to better capture the market realities and drive circular economy goals.

Conclusions The construction sector and the LCI database developers are encouraged to create the missing LCA databases compatible with the modular and end-of-life allocation modelling requirements of both methods. More prescriptive and meticulous guidelines, with further harmonization between the EC PEF method and the CEN standards and their end-of-life allocation formula, would largely increase comparability and reliability of LCA studies and communications. To improve transparency, it is recommended to report the module D impacts per life cycle stage as per the CEN standards and the burdens and benefits separately for each life cycle stage as per the EC PEF method.
\end{abstract}

Keywords Life cycle assessment (LCA) · Circular footprint formula (CFF) · Product environmental footprint (PEF) · EN 15804/ EN 15978 CEN standards · Sustainable building $\cdot$ End-of-life (EoL) allocation

Responsible Editor: Alexander Passer

Electronic supplementary material The online version of this article (https://doi.org/10.1007/s11367-020-01807-8) contains supplementary material, which is available to authorized users.

Sahar Mirzaie

sm76@hw.ac.uk; sahar.mirzaei.s@gmail.com

1 Institute for Sustainable Building Design, Heriot-Watt University, Edinburgh, Scotland EH14 4AS, UK
2 VITO/EnergyVille, Boeretang 200, B-2400 Mol, Belgium

3 Faculty of Engineering Science, Department of Architecture, Division of Architectural Engineering, KU Leuven, Kasteelpark Arenberg 1, box 2431, B-30O1 Leuven, Belgium 


\section{Introduction}

Life cycle assessment (LCA) is a quantitative method to assess the environmental impacts of products and services and can assist in informed decision making and policy development. Various LCA methods have been developed to date. The EN 15804/EN 15978 standards specifically focus on LCA of construction products and buildings and are part of the suite of standards developed by CEN/TC 350 (AFNOR Normalisation 2017). The CEN standard EN 15804+A1:2013 has been extensively used throughout Europe to establish environmental product declarations (EPDs) of construction products (Passer et al. 2015), while the EN 15978:2011 is used for the assessment of the life cycle environmental impact of buildings. Construction products EPDs issued annually have exponentially increased (Ibáñez-Forés et al. 2016). By May 2013, 27 European EPD programmes and 556 PCR documents were published based on ISO 14025 and EN 15804 (Hunsager et al. 2014). Integrating EPDs in streamlined LCA and design process of buildings, however, is still a challenge (Minkov et al. 2015).

In order to overcome the proliferation of environmental claims existing in the market (labels, certification schemes), the European Commission (EC) published the product environmental footprint (PEF) and organization environmental footprint (OEF) methods in 2013 (EC 2013). The main goal was to define a harmonized LCA method that allows a level field assessment of products and organizations in the European market. The aim was furthermore to enable comparison and benchmarking, reduce the assessment time and cost and create a single market for green products (EC 2017b). The PEF and OEF methods have been tested through various pilot studies from 2013 onwards. April 2018 marked the end of the pilot phase that tested the implementation of the methods under real market conditions. A total of 22 pilot product environmental footprint category rules (PEFCRs) and 2 pilot organization environmental footprint sectoral rules (OEFSRs) were developed, which consist of more detailed LCA rules for certain product groups in order to allow for comparative assertions of products within the defined product group. Although the PEF method is not focussing on buildings, its applicability has been tested for new office buildings in the PEF4Buildings project (VITO, KU Leuven and TU Graz 2018). The PEF4Buildings project provides an overview of the pros and cons of possible alternative approaches to the definition of benchmark and classes of performance for the typology of the two office buildings considered in the scope of the study.

The PEF method and CEN standards have similarities but also important differences. A limited number of studies have offered clarification about the theoretical differences of these methods (Finkbeiner 2014; Galatola and Pant 2014; Passer et al. 2015; Del Borghi et al. 2019; Durão et al. 2020).
However, no study has focused on the comparison of the implications of these variations in practice. They have theoretically assessed the discrepancies and possible convergence procedure between PEF and the CEN methods and concluded that their distinct requirements concede low comparability of their results and EPDs (Finkbeiner 2014; Passer et al. 2015; Bach et al. 2018; Del Borghi et al. 2019; Durão et al. 2020). The main findings of the respective papers of interest are summarized in Section 2. Given the intended outcomes of the PEF initiative and the mandate of the EC to align the CEN/TC 350 standards (CEN 2011, 2013; EC 2018) and the PEF method (EC 2017a) (for global consistency), further research is required to understand the differences between both methods better and gain insight into the implications of the changes in the CEN standards. An essential difference between both methods is the end-of-life (EoL) modelling approach and their allocation factors, which is less explored in the other studies and is the core of this work. This paper aims at providing insight on the EoL approaches in both methods when applied to a building in order to better understand the implications of each approach on the life cycle environmental impact allocated to the building assessed.

More specifically, this paper investigates on how both approaches can support more informed decisions towards achieving circular economy targets. Section 2 focuses on a theoretical comparison of the EoL approaches in the PEF (EC 2017a) and CEN standards (CEN 2011, 2013, 2019) and includes a proposal for an EoL formula for the CEN standards to increase consistency in the implementation of the standards and enhance comparability with the PEF approach. Section 3 presents a quantitative comparison of the influence of the EoL modelling approach of the PEF method and CEN (EN 15804+A1:2013 and EN 15978:2011) standards on the LCA results of the case-study building (newly built non-domestic building in Scotland, known as the Lyell building). Section 4 focuses on the interpretation of the results, and Section 5 summarizes the main findings and formulates recommendations for further research.

\section{Theoretical comparison of the EoL approach in PEF and CEN}

For the theoretical comparison of the EoL approaches in the CEN standards and PEF method, the main documents that were considered besides the scientific literature were EN 15804:2012+A1:2013 (CEN 2013), EN 15804:2012+ A2:2019 (CEN 2019), EN 15978:2011 (CEN 2011), and the PEFCR Guidance v6.3 (EC 2017a). For further clarification to the CEN standards, some additional documents were consulted: the first edition of "Whole life carbon assessment for the built environment" RICS professional statement (RICS 2017), the second revision of the BRE global product category 
rules (PCR) for type III EPD of construction products to EN 15804+A1 (BRE Group 2018) and the second version of PCR for buildings published by the International EPD® System (EPD International 2018). Moreover, the PEFCR Guidance v6.3 was cross-examined with the PEF guide (EC 2013), the PEF4Buildings report (VITO, KU Leuven and TU Graz 2018) and the available construction products PEFCRs (or final drafts), which were metal sheets, decorative paints, thermal insulation for roofs and water distribution piping systems (Technical Secretariat of the PEF Thermal Insulation Pilot 2016; Technical Secretariat PEF Pilot on Piping Systems 2016; Thinkstep AG 2016; Technical Secretariat Decorative Paints 2018).

Before focussing on the EoL approach in both methods, it is necessary to highlight some other notable differences between the two methods that relate to the EoL modelling.

\subsection{General differences in PEF and CEN relevant to the EoL modelling approaches}

First, it is acknowledged that the main objectives of the CEN standards and the PEF method differ. The main objective of the CEN standards is to ease and encourage transparent reporting of the environmental impact of construction products and buildings considering their whole life cycle. The CEN standards are not prescriptive and offer flexibility in the calculation and assumptions, such as defining system boundaries, selecting data sources, and choosing allocation methods. While this is meant to simplify the calculation challenges, the variety of methodological choices impairs the reproducibility, comparability and consistency of the outcomes (Lasvaux et al. 2014; Passer et al. 2015). In contrast with the CEN approach, the main objective of the PEF method is harmonization, robustness, and comparability through the development of strict PEFCRs and identifying a single method or detailed guidance at every decision point (Passer et al. 2015). The PEF methodology prescribes an EoL formula that is mandatory to be applied when conducting a PEF study to ensure consistency, while the CEN standards only describe the EoL approach textually without providing an EoL formula. The latter opens the door for interpretation and hence reduces the comparability and consistency of EPDs, or LCA studies of buildings following the CEN standards.

Second, the scope and system boundaries of both methods differ. The EN 15804:2012 + A1:2013 standard (CEN 2013) imposed only the production stage and left the assessment of all other life cycle stages optional, while EN 15804:2012+ A2:2019 (CEN 2019) requires to study all life cycle stages except construction and use stages. A modular structure is used to clearly report the environmental impact in the life cycle stage where these occur. On the contrary, for assessments compatible with the PEF method, all life cycle stages shall be reported. Unlike the CEN standards, the PEF
Guidance does not break down these stages to life cycle modules. The relevant life cycle modules for each product are advised in its PEFCR, along with the technical requirements and assumptions to be used for LCA modelling. Three differences are furthermore identified in the modular reporting:

- The system boundaries related to recycling, reuse and energy recovery at the product EoL differ between the methods: in the CEN standards, if these burdens and benefits occur before or after product has reached the "end-ofwaste" state then they are declared in module $\mathrm{C}$ or are considered beyond the system boundaries and shall be declared separately (in module D), respectively. While in the PEF method these burdens and benefits are included in the module when they occur (and allocated partially to both products related to the recycling and reuse processes). Accordingly, due to differences in the system boundaries, the EoL module D does not exist in the PEF approach. This approach is reflected similarly at the production stage when a product consists of recycled content. In the CEN standards, the benefits and burdens related to the recycled content are fully allocated to the construction product/building (the user of the recycled material) and reported in modules $\mathrm{A} 1$ and $\mathrm{A} 2$.

- In the CEN standards, modules A1, A2 and A3 may be declared as one aggregated module covering the "cradle to gate" processes for the materials and services used in the construction (CEN 2013, 2019). While according to the PEFCR Guidance v6.3 (EC 2017a), the manufacturing processes, the raw material acquisition and pre-processing, and product distribution and storage need to be reported separately from one another.

- In the CEN standards, the impacts of various waste flows are reported in distinct modules $(\mathrm{C} 3, \mathrm{C} 4$ and $\mathrm{D})$ according to specific criteria. In the PEF approach, all waste flows are reported collectively regardless of their treatment, i.e. landfill, incineration and recycling.

Third, the five PEFCRs for construction products developed during the PEF Pilot phase, namely metal sheets, decorative paints, thermal insulation for roofs, $\mathrm{PV}$ and water distribution piping system, follow the modular approach of the CEN standards, i.e. they prescribe to report the impacts in a life cycle modules. However, various PEFCRs define these modules differently. For instance, paints have 15 and metal sheets have only four life cycle modules. Although this incompatibility does not present any problem in intra-product comparisons, it exacerbates the challenge of aggregation of EPD data (based on these PEFCRs) at the overarching building level (VITO, KU Leuven and TU Graz 2018). In the PEF4Buildings project, a modular structure, similar to the CEN, with clearly defined system boundaries was proposed and is followed in this paper (see Table 1). 
Table 1 Life cycle stages for an assessment at the building level (CEN 2011, 2013, 2019; EC 2017a; VITO, KU Leuven and TU Graz 2018)

\begin{tabular}{|c|c|c|c|}
\hline \multirow[t]{2}{*}{ Life cycle stage } & \multicolumn{3}{|c|}{ Life cycle module } \\
\hline & PEF & CEN & Description \\
\hline \multirow[t]{3}{*}{ Product stage } & A1 & A1 & $\begin{array}{l}\text { Raw material extraction and processing, pre-processing of } \\
\text { secondary material input and packaging of raw materials }\end{array}$ \\
\hline & $\mathrm{A} 2$ & A2 & $\begin{array}{l}\text { Transport of virgin and recycled materials to the factory } \\
\text { gate and internal transport }\end{array}$ \\
\hline & A3 & A3 & Manufacturing of the products and the related packaging \\
\hline \multirow[t]{2}{*}{ Construction stage } & A4 & A4 & Transport to the building site \\
\hline & A5 & A5 & $\begin{array}{l}\text { Construction and installation into the building processes, } \\
\text { including all ancillary materials, EoL of the packaging } \\
\text { material disposed, and losses during construction }\end{array}$ \\
\hline \multirow[t]{7}{*}{ Use stage } & B1 & B1 & Use or application of the installed product \\
\hline & $\mathrm{B} 2$ & $\mathrm{~B} 2$ & Maintenance (planned cleaning, servicing activities) \\
\hline & B3 & B3 & Repair (responsive or reactive treatment actions) \\
\hline & B4 & B4 & Replacement of a whole construction element \\
\hline & B5 & B5 & $\begin{array}{l}\text { Refurbishment (maintenance, repair and replacement } \\
\text { of a whole section of the building) }\end{array}$ \\
\hline & B6 & B6 & Operational energy use \\
\hline & B7 & B7 & Operational water use \\
\hline \multirow[t]{4}{*}{ EoL stage } & $\mathrm{C} 1$ & $\mathrm{C} 1$ & Dismantling, demolition and on-site sorting \\
\hline & $\mathrm{C} 2$ & $\mathrm{C} 2$ & Transport to waste processing destination \\
\hline & \multirow[t]{2}{*}{$\mathrm{C} 3-\mathrm{C} 4$} & $\mathrm{C} 3$ & $\begin{array}{l}\text { Waste processing for reuse, recycling or energy recovery } \\
\text { with more than } 60 \% \text { efficiency }\end{array}$ \\
\hline & & $\mathrm{C} 4$ & $\begin{array}{l}\text { Disposal (landfill, incineration, and waste processing for } \\
\text { energy recovery with less than } 60 \% \text { efficiency) }\end{array}$ \\
\hline Supplementary information & Not applicable & $\mathrm{D}$ & $\begin{array}{l}\text { Benefits and loads beyond the system boundaries for } \\
\text { reuse, recovery, or recycling potentials, expressed } \\
\text { as net impacts and benefits }\end{array}$ \\
\hline
\end{tabular}

Finally, allocation is another aspect that is applied differently in the two methods. For handling product multifunctionality and co-product allocation, both the PEF method and CEN standards recommend a comparable approach, yet a specific ratio is provided in the EN 15804 to define the borderline between physical and economic allocation (CEN 2013; EC 2017a). In PEF, subdivision and system expansion are preferred methods over allocation (based on physical or other relationships). The CEN method does not accept avoiding allocation by expanding the system boundary due to modularity and polluter pays principles and the attributional approach of this standard Del Borghi et al. 2019.

\subsection{EoL modelling approach in the PEF method and CEN standards}

The CEN approach sets the EoL system boundary where outputs of the system under study have reached the "end-ofwaste" state according to the modularity and polluter pays principles (CEN 2013). Unlike CEN, PEF defines it as "until the product is returned to nature as a waste or enters another product's life cycle" (EC 2013). The system boundary in the
PEF Guidance v6.3 systematically allocates burdens and credits between consumer and producer reflecting market demand and supply realities and both aspects of recycling: recycled content and recyclability at EoL, using the "Circular Footprint Formula" (CFF) (EC 2013, 2017a). Note that this is different from the original PEF formula, where market reality was not considered, and a 50/50 allocation (50\% allocated to the consumer and $50 \%$ to the producer) was used for all products.

The EoL allocation procedures in the CEN standards are according to the polluter pays principle, also known as the cutoff or 100-0 approach, which states that the loads from the production of material are allocated to the primary user of that material. As per this principle, when a material or waste leaves the product system boundary as secondary material or fuel, processes, such as collection and transport before the "end-ofwaste" state are included in the product system under study. While processes after having reached the "end-of-waste" state, which are required to reach functional equivalence to replace primary material or fuel input in another product system, are beyond the system boundary and can voluntarily be declared in module D. Thus, secondary (recycled) materials bear the 
impacts of the recycling processes, and the loads and benefits from recycled content are included in module A1. Similarly, if energy is recovered from waste (for instance, heat from the incineration of municipal solid waste), the burdens lay with the waste producer, fully allocated to the treatment of the waste; therefore, the energy comes burden-free (CEN 2013). This approach is also known as upstream allocation, which is the approach used in the Ecoinvent "recycled content" database (ecoinvent 2020).

In the CEN modelling approach, when the "end-of-waste" state is reached and a material or waste is recycled, the producer of recycled material can declare credits for the avoided primary material production only in module $\mathrm{D}$, which provides additional information beyond the system boundaries (called "benefits and loads beyond the product system boundary"). Module $\mathrm{D}$ provides transparency to the net environmental benefits or loads resulting from secondary materials or fuels leaving the product system boundary, i.e. net impacts due to recycling, recovery or reuse at EoL are deducted from those arising from recycled content in the production stage in order to avoid double counting (CEN 2013, 2019). For example, if a reinforcing steel with 54\% recycled content is used to build a building and after building demolition $96 \%$ of the reinforcing steel is recycled, then the net benefit (due to avoided virgin steel) that can be considered in module $\mathrm{D}$ because of recycling at EoL equates to $42 \%$.

As mentioned before, the PEF Guidance v6.3 document includes an EoL (allocation) formula, referred to as the Circular Footprint Formula (CFF). The CFF is represented in Table 2-second column. The parameters are in line with the PEFCR Guidance Document (EC 2017a) (and are described in Appendix A of the Supplementary Information). Emissions and consumed-resources arising from transport to the recycling plant are included in the CFF in $E_{\text {recycled }}$ and $E_{\text {recyclingEOL. In line with the life cycle modules }}$ presented in Table 1, the transport impacts have been separated from the recycling processes and have been included in the formula as $E_{\text {freight }} \times$ Dist $\times$ UR to simplify the understanding and application of the formula, where Dist is distance and $E_{\text {freight }}$ is emissions and consumed-resources arising from a unit (e.g. $1 \mathrm{~kg} \mathrm{~km})$ of freight transport and depends on the medium of transport. UR or utilization ratio depends on the type of material transported and is defined as the ratio of the real load divided by the payload. The payload is the maximum mass allowed for the transport medium, e.g. the payload of a 28-32t truck is 22t (EC 2017a). The parameter " $A$ " is the allocation factor of burdens and credits between supplier and user of recycled materials. " $\mathrm{A}$ " is added to the CFF formula to be able to reflect the market realities of user demand and supplier offer for different products, as mentioned before. For instance, when there is a low demand for a waste type, such as timber products, " $\mathrm{A}$ " has a high value, e.g. 0.8 , to encourage the user and focus the market on rewarding recycled content. When there is a high demand or low offer for a material, such as steel, "A" has a lower value, e.g. 0.2 , to reward the supplier and focus on designing for recyclability. When there is a relative equilibrium between offer and demand or the market has not been studied yet, a default 50 50 value is considered, meaning " $\mathrm{A}$ " is 0.5 .

The CEN modelling principles are described in the CEN standards, but no calculation formula is provided (EC-JRCInstitute for Environment and Sustainability 2010; CEN 2011, 2013). A calculation formula was hence developed by the authors of this paper using identical parameters as in the CFF of the PEF Guidance v6.3 and is presented in the third column of Table 2. The CFF formula from the PEFCR Guidance Document v6.3 (EC 2017a) is rearranged as per the CEN modelling principles. This consistent modular formula helps the application and comparison of the two methods in practice.

Module A3 includes energy and materials used in the manufacturing process of all the materials, i.e. electricity or diesel for running and water or oil for cooling the production machines. These types of inputs do not include recycled content, and the outputs are never recycled; hence, no EoL allocation is applied. Therefore, this module is equal in both methods and is not included in Table 2.

\section{Comparative building assessment in line with the PEF method and CEN standards}

To compare the outcomes of applying the PEF and CEN methods at the building level, this section considers a casestudy building and describes the procedure, challenges and results of modelling following both LCA methods.

\subsection{Modelling the case-study building}

The Lyell building is a research centre for earth and marine science and technology, mainly consisting of open office space and some laboratories and meeting rooms. As Fig. 1 shows, the Lyell building has four storeys, three above ground and one below ground. The building structure consists of a steel frame with in-situ concrete floor slabs on ground beam foundations with some retaining structures (Table 3). The construction started in 2014 and was completed in February 2016. The building internal net (or conditioned) floor area is $5370\left[\mathrm{~m}^{2}\right]$. The Lyell building achieved a B-rated Energy Performance Certificate (EPC) with projected $72\left[\mathrm{kWh} / \mathrm{m}^{2}\right]$ annual energy use and $21.95\left[\mathrm{kgCO}_{2} \mathrm{eq} / \mathrm{m}^{2}\right]$ annual carbon dioxide emissions. Metered electricity $(47,100[\mathrm{kWh}])$, gas $(1,308,343[\mathrm{kWh}])$, and water consumption $\left(1241.42\left[\mathrm{~m}^{3}\right]\right)$, and on-site PV electricity production $(6340[\mathrm{kWh}])$ of the Lyell building, during the second year of occupation, were used for modelling modules B6 and B7. 
Table 2 CFF formula from PEF (EC 2017a) and proposal for EoL formula for the CEN EN15804/EN15978 standards

\begin{tabular}{|c|c|c|c|}
\hline Module & \multicolumn{2}{|l|}{ PEF - CFF formula } & CEN/TC 350 - Suggested Formula \\
\hline A1 & \multicolumn{2}{|c|}{$\begin{array}{l}\left(1-\mathrm{R}_{1}\right) \times \mathrm{E}_{\mathrm{V}}+(1-\mathrm{A}) \times \mathrm{R}_{1} \times \mathrm{E}_{\mathrm{V}} \times Q_{S, \text { in }} / Q_{P} \\
+\mathrm{R}_{1} \times \mathrm{E}_{\text {recycled }}-(1-\mathrm{A}) \mathrm{R}_{1} \times \mathrm{E}_{\text {recycled }}\end{array}$} & $\begin{array}{l}\left(1-\mathrm{R}_{1}\right) \times \mathrm{E}_{\mathrm{V}} \\
+\mathrm{R}_{1} \times \mathrm{E}_{\text {recycled }}\end{array}$ \\
\hline A2 & \multicolumn{2}{|c|}{$\begin{array}{l}\left(1-\mathrm{R}_{1}\right) \times \mathrm{E}_{\text {freight }} \times \text { Dist }_{\mathrm{v}} \times \mathrm{UR}_{\mathrm{v}}+(1-\mathrm{A}) \times \mathrm{R}_{1} \times Q_{S, \text { in }} / Q_{P} \times \\
\mathrm{E}_{\text {freight }} \times \text { Dist }_{\mathrm{v}} \times \mathrm{UR}_{\mathrm{v}} \\
+\mathrm{R}_{1} \times \mathrm{E}_{\text {freight }} \times \operatorname{Dist}_{\text {recycled }} \times \mathrm{UR}_{\text {recycled }}-(1-\mathrm{A}) \times \mathrm{R}_{1} \times \\
\mathrm{E}_{\text {freight }} \times \operatorname{Dist}_{\text {recycled }} \times \mathrm{UR}_{\text {recycled }}\end{array}$} & $+\mathrm{R}_{1} \times \mathrm{E}_{\text {freight }} \times$ Dist $_{\text {recycled }} \times \mathrm{UR}_{\text {recycled }}$ \\
\hline $\mathrm{C} 2$ & \multicolumn{2}{|c|}{$\begin{array}{l}+(1-\mathrm{A}) \times \mathrm{R}_{2} \times \mathrm{E}_{\text {freight }} \times \text { Dist }_{\text {recyclingEoL }} \times \mathrm{UR}_{\text {recyclingEoL }} \\
+(1-\mathrm{B}) \times \mathrm{R}_{3} \times \mathrm{E}_{\text {freight }} \times \mathrm{Dist}_{\mathrm{ER}} \times \mathrm{UR}_{\mathrm{ER}} \\
+\left(1-\mathrm{R}_{2}-\mathrm{R}_{3}\right) \times \mathrm{E}_{\text {freight }} \times \operatorname{Dist}_{\mathrm{D}} \times \mathrm{UR}_{\mathrm{D}} \\
-(1-\mathrm{A}) \times \mathrm{R}_{2} \times Q_{S, \text { out }} / Q_{P} \times \mathrm{E}_{\text {freight }} \times \text { Dist }_{\mathrm{v}} \times \mathrm{UR}_{\mathrm{v}}\end{array}$} & $\begin{array}{l}+\mathrm{R}_{2} \times \mathrm{E}_{\text {freight }} \times \mathrm{Dist}_{\text {recyclingEoL }} \times \mathrm{UR}_{\text {recyclingEoL }} \\
+\mathrm{R}_{3} \times \mathrm{E}_{\text {freight }} \times \mathrm{Dist}_{\mathrm{ER}} \times \mathrm{UR}_{\mathrm{ER}} \\
+\left(1-\mathrm{R}_{2}-\mathrm{R}_{3}\right) \times \mathrm{E}_{\text {freight }} \times \operatorname{Dist}_{\mathrm{D}} \times \mathrm{UR}_{\mathrm{D}}\end{array}$ \\
\hline $\mathrm{C} 3-\mathrm{C} 4$ & \multicolumn{2}{|c|}{$\begin{array}{l}+(1-\mathrm{A}) \mathrm{R}_{2} \times \mathrm{E}_{\text {recyclingEoL }} \\
-(1-\mathrm{A}) \mathrm{R}_{2} \times \mathrm{E}_{\mathrm{V} \text {, out }}^{*} \times Q_{S, \text { out }} / Q_{P} \\
+\left(1-\mathrm{R}_{2}-\mathrm{R}_{3}\right) \times \mathrm{E}_{\mathrm{D}} \\
+(1-\mathrm{B}) \mathrm{R}_{3} \times \mathrm{E}_{\mathrm{ER}} \\
-\mathrm{R}_{3} \times\left(\mathrm{LHV} \times \mathrm{X}_{\mathrm{ER}, \text { elec }} \times \mathrm{E}_{\mathrm{SE}, \text { elec }}+\mathrm{LHV} \times \mathrm{X}_{\mathrm{ER} \text {, heat }} \times\right. \\
\left.\mathrm{E}_{\mathrm{SE}, \text { heat }}\right)\end{array}$} & $\begin{aligned} \mathrm{C} 3= & +\mathrm{R}_{2} \times \mathrm{E}_{\text {recyclingEoL }} \\
& +\mathrm{R}_{3} \times \mathrm{E}_{\mathrm{ER}} \quad \leftarrow \text { if efficiency }>60 \% \\
\mathrm{C} 4= & +\mathrm{R}_{3} \times \mathrm{E}_{\mathrm{ER}} \quad \leftarrow \text { if efficiency }<60 \% \\
& +\left(1-\mathrm{R}_{2}-\mathrm{R}_{3}\right) \times \mathrm{E}_{\mathrm{D}}\end{aligned}$ \\
\hline $\mathrm{D}$ & \multicolumn{2}{|c|}{ Not Applicable - Reflected in the relevant module $\uparrow$} & 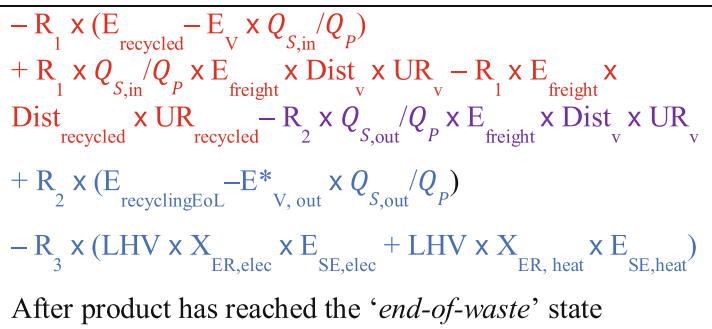 \\
\hline \multicolumn{4}{|c|}{ Parameters are defined in line with the PEFCR Guidance Document: } \\
\hline \multirow{3}{*}{\multicolumn{2}{|c|}{$\begin{array}{l}\mathrm{A}=\text { allocation factor of burdens } \\
\text { and credits between supplier } \\
\text { and user of recycled materials } \\
\mathrm{B}=\text { allocation factor of energy } \\
\text { recovery processes }\end{array}$}} & \multirow[t]{2}{*}{$\begin{array}{l}\mathrm{E}_{\text {freight }}=\text { emissions and } \\
\text { consumed-resources arising } \\
\text { from a unit }(\mathrm{e} . \mathrm{g} .1 \mathrm{~kg} . \mathrm{km}) \text { of } \\
\text { freight transport }\end{array}$} & \multirow{2}{*}{$\begin{array}{l}E_{v}=\text { emissions and consumed-resources arising from } \\
\text { acquisition and processing of virgin material } \\
E_{\text {recycled }} \text { emissions and consumed-resources arising } \\
\text { from recycling of recycled (reused) material }\end{array}$} \\
\hline & & & \\
\hline & & Dist $=$ Distance & \multirow{4}{*}{$\begin{array}{l}\mathrm{E}_{\mathrm{v}}^{*}=\text { emissions and consumed-resources arising from } \\
\text { acquisition and pre-processing of virgin material } \\
\text { assumed to be substituted by recyclable materials at EoL } \\
\mathrm{E}_{\text {recycling,EoL, }} \mathrm{E}_{\mathrm{ER}} \text {, and } \mathrm{E}_{\mathrm{D}}=\text { emissions and consumed- } \\
\text { resources arising from, recycling process, energy } \\
\text { recovery process, and disposal of waste material } \\
\text { (without energy recovery) at EoL, respectively }\end{array}$} \\
\hline \multirow{2}{*}{\multicolumn{2}{|c|}{$\begin{array}{l}\mathrm{R}_{1}=\text { proportion of material in } \\
\text { input to production that has } \\
\text { been recycled from a previous } \\
\text { system }\end{array}$}} & UR $=$ Utilisation Ratio & \\
\hline & & $\begin{array}{l}Q_{p}=\text { quality of primary or } \\
\text { virgin material }\end{array}$ & \\
\hline \multirow{2}{*}{\multicolumn{2}{|c|}{$\begin{array}{l}\mathrm{R}_{2} \text { and } \mathrm{R}_{3}=\text { proportions of } \\
\text { material in product that, } \\
\text { respectively, will be recycled } \\
\text { (or reused) in another system } \\
\text { and will be used for energy } \\
\text { recovery at EoL }\end{array}$}} & $\begin{array}{l}\mathrm{Q}_{\mathrm{s}, \mathrm{in}}=\text { quality of ingoing } \\
\text { secondary materials at the point } \\
\text { of substitution }\end{array}$ & \\
\hline & & $\begin{array}{l}\mathrm{Q}_{\mathrm{s}, \text { out }}=\text { quality of outgoing } \\
\text { secondary material at the point } \\
\text { of substitution }\end{array}$ & $\begin{array}{l}E_{\mathrm{SE}, \text { heat }} \text { and } \mathrm{E}_{\mathrm{SE}, \mathrm{elec}}=\text { emissions and consumed-resources } \\
\text { that would have arisen from the specific substituted } \\
\text { energy source, heat and electricity, respectively }\end{array}$ \\
\hline \multicolumn{2}{|c|}{$\begin{array}{l}\mathrm{M}=\text { amount of material flow } \\
\mathrm{Q}=\text { quality of material flow }\end{array}$} & $\begin{array}{l}\text { LHV = Lower Heating Value of } \\
\text { material used for energy } \\
\text { recovery }\end{array}$ & $\begin{array}{l}\text { ' } \mathrm{X}_{\mathrm{ER}, \text { heat }} \text { ' and ' } \mathrm{X}_{\mathrm{ER}, \text { elec' }}=\text { efficiency of energy recovery } \\
\text { process for heat and electricity }\end{array}$ \\
\hline
\end{tabular}


Table 3 Materials and building elements considered in the LCA system boundary

\begin{tabular}{ll}
\hline Element group & Building elements and components \\
\hline Substructure & Foundation, including excavations, basement retaining walls, \\
lowest floor slab (slab on earth) \\
Superstructure & Structural frame, including primary and roof beams, columns, \\
& tie beams and edge beams \\
& Upper floors, including balconies (in-situ concrete floor slabs) \\
& Roof (liquid plastics system on tapered insulation) \\
& Stairs and ramps \\
& External walls: steel-frame and fair-faced brickwork cladding \\
& and curtain walling \\
Windows and metal external doors & Interior walls: partitioning (metal-framed plasterboard), \\
plywood, concrete block, internal glazed walls & Internal finishes: floorings, ceilings (metal framed plasterboard), \\
& walls (paint and plasterboard) \\
Interiors & Timber doors with glazing \\
& Mechanical, electrical, and plumbing elements: heating equipment \\
& (combined heat and power engines and condensing boilers), \\
& ventilation and air-conditioning equipment (chillers and fan coils), \\
photovoltaic solar system, sanitary, lighting, lift, safety, security, \\
communication installations
\end{tabular}

\subsubsection{Scope and system boundaries of the Lyell building}

The system boundaries of the study are set to the whole building, including its foundations, but excluding the external works as presented in Fig. 1. This includes the buildingintegrated technical systems and building-related fixtures and fittings. The domestic, commercial and industrial appliances, such as washing machines, refrigerators, cooking appliances and office electronics are excluded in line with the EN 15978 and RICS recommendation (CEN 2011; RICS 2017). An overview of the materials and building elements considered in the scope of the LCA study is provided in Table 3. The Reference Service Life (RSL) and Reference Study Period (RSP) are both defined based on the structural design life of 60 years, which is also prescribed in the EN15978 and RICS guide and for non-domestic projects under BREEAM 2014 NC-Mat 01 life cycle impact (CEN 2011; BRE Global Ltd. 2014; RICS 2017). This study was carried out from cradle to grave, except module B1: Use and B5: Refurbishment, as module B1 was considered trivial and no refurbishment scenarios were foreseen for the building at the time of the study. The reference flow is the total amount of materials (including water) and energy needed for the building to perform its function during the service life of 60 years.

Detailed project documentation was used to develop the building life cycle inventory (LCI), including BIM (building information modelling) files (Fig. 1), architectural, structural, and building services drawings and specifications; price schedules; EPC energy analysis models; and BREEAM documentation, which were shared confidentially with the authors.

The LCI of the building elements, sub-elements, and materials was developed in a spreadsheet format following the modularity principle discussed in Section 2.2, clarifying the applicable scenarios at each life cycle module. The LCI data were moreover structured in a hierarchical way following the element method. More specifically, quantities of materials have been specified per unit of each building element and the amount of each building element was determined, in line with the tree-like building element classification system
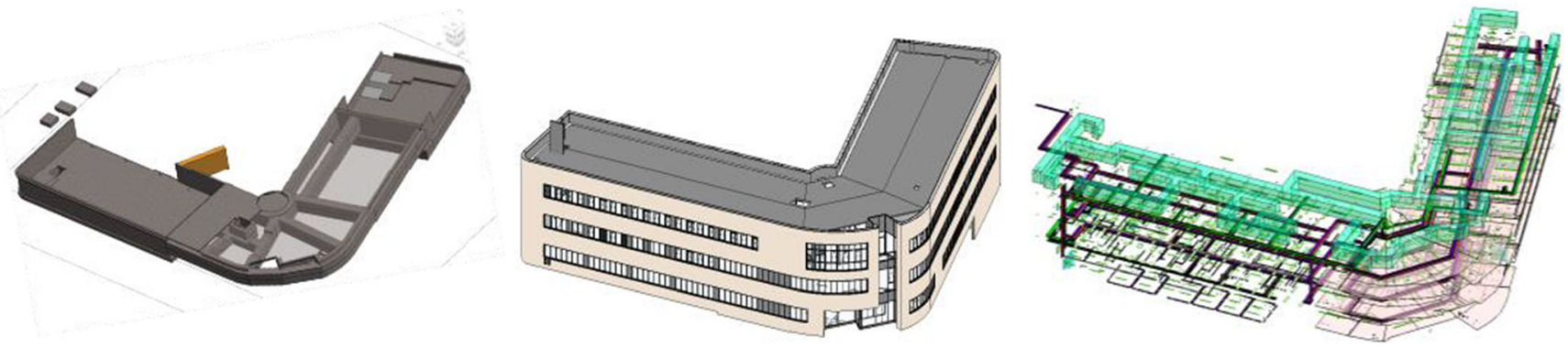

Fig. 1 Graphical representation of the foundation, architectural and building services model of the Lyell building (from left to right) 
introduced in ISO 12006-2 and used in similar studies (Allacker 2010; ISO 2015; Trigaux et al. 2017; VITO, KU Leuven and TU Graz 2018). This hierarchical structure allows identifying the hotspots in terms of most relevant materials and most relevant building elements when assessing the life cycle impact of the building, which is seen as an added value to the designers for model validation and decision support. This is, moreover, the same approach that BREEAM has used for the assessment and improvement of building life cycle impacts (BRE Ltd. 1996). The building elements considered in the modelling are as per the RICS guide (RICS 2017) and are summarized in Table 3.

\subsubsection{Recycled content and EoL assumptions}

Annex C of the PEFCR Guidance v6.3 (EC 2017a) prescribes default recycled content values $\left(\mathrm{R}_{1}\right)$ and allocation factors $(A)$ to be used for various materials on the EU market. For the Lyell building, these PEFCR Guidance values were used. The EoL scenarios $\left(\mathrm{R}_{2}, \mathrm{R}_{3}\right.$, and Ratio Landfilled) were based on national and local guidelines, based on the RICS Guide (RICS 2017). The RICS Guide assembled recovery and disposal rates for timber, steel, aluminium, copper, and general demolition waste as per the DEFRA report called "UK statistics on waste" (DEFRA 2018) to be used as default scenarios for EoL modelling (RICS 2017). The considered scenarios are presented in supplementary information-Appendix C. The same scenarios were used for modelling as per both PEF and CEN approaches.

\subsubsection{Impact assessment method and hotspot analysis}

The EN 15804+A1 standard used the CML method for the Life Cycle Impact Assessment (LCIA), considering seven environmental impact categories, while the PEF uses the EF method considering sixteen indicators. For the sake of comparability of results and because a comparison of the CEN and PEF impact assessment indicators and characterization factors is beyond the scope of this paper, the same indicators and characterization factors were used for both methods. More specifically, the environmental impacts of the Lyell building are assessed using the EF method v2.0 impact categories (listed in Table 4 and Appendix D of the Supplementary Information) and characterization, normalization, and weighting factors as per PEFCR Guidance v6.3 (EC 2017a; Sala et al. 2017). The EF method was chosen for the impact assessment according to both the PEF and CEN approaches because it is more comprehensive than the CML method. Further insights regarding the difference in indicators of both methods can be found in Passer et al. (2015) who listed these indicators against each other and in Allacker et al. (2016) who reviewed the adequacy of the seven CEN impact categories along with the pertinence of additional environmental indicators.

The hotspots were identified following the rules of the PEFCR Guidance document v6.3 (EC 2017a). The hotspots are the most relevant environmental indicators, life cycle stages, building elements and construction materials. Due to the presence of negative and positive values in the results, the summation would cancel out some of the outcomes; therefore, to avoid any distorted perception of the total results, the PEF Guidance requires the absolute normalized and weighted results to be used for identifying the hotspots.

The most relevant impacts in each grouping must cumulatively contribute to at least $80 \%$ of the total environmental impacts. If the contribution of the use phase is more than $50 \%$, the analysis was repeated excluding that hotspot to identify the other relevant groups. First, the most relevant environmental indicators are identified, and then for each one of the most relevant indicators, the most relevant life cycle stages, building elements, and construction materials (as processes at different levels of detail) are determined. The three toxicity indicators must be excluded and communicated separately. This decision is temporarily in place and will be reconsidered at the end of the PEF transition phase in 2020 (EC 2017a). In this work, the results are interpreted with and without the toxicity indicators to identify the influence of their inclusion.

\subsection{Creating datasets to allow for a modular EoL modelling}

At the time of the study, neither the EF-compliant datasets commissioned by the EC nor other datasets were available to model the $\mathrm{LCI}$ in line with both $\mathrm{PEF}$ and $\mathrm{CEN}$ requirements and apply the CFF. Therefore, the generic Ecoinvent database version 3.3, allocation, cut-off by classification, compiled in October 2016 (ecoinvent 2020), was used. As described in Section 2.2, allocation, cut-off by classification is based on the recycled content approach, which is compliant with the EN 15804:2012+A1:2013 standard (CEN 2013) and is adaptable to the PEF requirements to implement the CFF (EC 2017a) and to model the project LCI as per the project specifications and manufacturer data.

The PEF Guide requires the use of specific (or primary) data for foreground processes, which refers to the processes under the direct operational control of the producer. In buildings, all products are procured from elsewhere; therefore, the PEF4Buildings project interpretation was adopted that assumed the use of specific data would not be mandatory for assessments at the building level (VITO, KU Leuven and TU Graz 2018).

SimaPro was chosen as LCA modelling software because it offers access to broad and adjustable databases that provide 
Table 4 Environmental impact indicators considered as per PEF
Environmental impact categories

Climate change (GWP)

Ozone depletion (ODP)

Ionizing radiation-human health, HH (IRP)

Photochemical ozone formation, HH (POFP)

Respiratory inorganics/particulate matter (PMFP)

Human toxicity, non-cancer (HTP-nc)

Human toxicity, cancer (HTP-c)

Ecotoxicity freshwater (aquatic) (FETP)
Acidification terrestrial and freshwater (AP)

Eutrophication - terrestrial (TEP)

Eutrophication - freshwater (FEP)

Eutrophication - marine (MEP)

Land use (LU)

Water scarcity/resource use-water (WRD)

Resource use, energy carriers/fossils (RD-E\&F)

Resource use, mineral and metals/non-fossil (RD-MM) information on the environmental impact of materials and processes, and flexibility in modelling (SimaPro UK Ltd 2020).

In Ecoinvent, modules A1 to A3 are most often reported jointly as "product stage". As mentioned before, it is allowed by $\mathrm{CEN}$ to report these jointly, and hence remodelling of the datasets is not strictly needed. If recycled content is, however, present in the construction products, the CFF formula requires the allocation of the burdens and benefits related to the recycled content between the successive systems (see Table 2). Hence, the Ecoinvent datasets were split to be able to differentiate module A1 to A3 at the product stage and model virgin $\left(E_{\mathrm{v}}\right)$, recycled $\left(E_{\text {recycled }}\right)$ and avoided virgin materials at the EoL $\left(E^{*}{ }_{\mathrm{v}}\right)$ as per the CFF formula. An example of this splitting of an Ecoinvent dataset is described in Appendix B in the Supplementary Information. Module A1 of materials with recycled content, e.g. cast iron, was modelled using two datapoints: one representing the virgin resources $\left(E_{\mathrm{v}}\right)$ and another the recycled content $\left(E_{\text {recycled }}\right)$. It was assumed that the energy and water use of the manufacturing process (module A3) was identical for production with either virgin or recycled materials. It is hence expected that this split may not always provide an accurate account of the environmental impacts occurring in each module, for which specific knowledge of material and production technology, beyond the scope of this study, is necessary. Besides, transportation of the raw materials is often covered in construction products in Ecoinvent, but these are not always declared as transport flow explicitly and separately; hence, these could not always be excluded. For example, in the "normal concrete production" data record, transport of resources is included and is reflected in the input flow "Diesel used" and output flows "emissions to air or water". These flows however include fuel used both for transport and at the production plant, without distinguishing both. For these construction products, transport in module A2 is likely to be overestimated due to possible double counting of the transport of the raw materials. This is the same approach as the one followed in the PEF4Buildings project (VITO, KU Leuven and TU Graz 2018). Although this approach has its limitations, it is required for the practical needs of this research.
In rare cases, where Ecoinvent did not include a dataset, the ELCD v3.2 and Industry data 2.0 (for plastics) databases were used, in order of preference. For instance, the electricity mix of the United Kingdom from the ELCD database was used (electricity mix, AC, consumption mix, at consumer, < $1 \mathrm{kV} \mathrm{GB}$ ) as the closest representative data where the operation takes place. Any data gaps were filled using the best available generic or extrapolated data. Efforts were made to use the latest versions of the reference databases.

The CFF parameters were defined for the relevant LCI materials using the formulae presented in Table 2.

\subsection{LCA results of the Lyell case study building}

\subsubsection{Life cycle impacts at the building level}

The characterized results of the Lyell case study following the methodological rules of the PEF and CEN methods are presented in Fig. 2, comparing the relative results for the two modelling approaches. The $\mathrm{C} 3$ and $\mathrm{C} 4$ modules are reported jointly for both the CEN and PEF results to allow comparability. In order be able to compare all indicators on one graph, the environmental impact of each indicator is presented on a scale of $100 \%$ with the highest impact value of both methods set to $100 \%$. The modules with net benefits (negative values) are also shown on the graph (not included in the 100\%). Figure 2 shows that the CEN method results in a higher burden for all environmental indicators (except for the eutrophication of freshwater). This is because the PEF method reports the beneficial contribution of avoided impacts at each life cycle module where they occur, while in the CEN method any avoided impact (benefit) is considered beyond the system boundary in module D (benefits from stage A1 (material acquisition), A2 (manufacturing transport), A5 (construction loss), B3 (repair), B4 (replacement), C2 (waste transport) and $\mathrm{C} 3-\mathrm{C} 4$ (waste processing and disposal)). The characterized benefits (negative values) are hence larger in the CEN method, while the burdens are typically also higher according to $\mathrm{CEN}$ (as for PEF, these are net impacts (i.e. burdens benefits)). The difference between the two methods is manifested in modules A1, A2, C2, C3-C4 and D. 


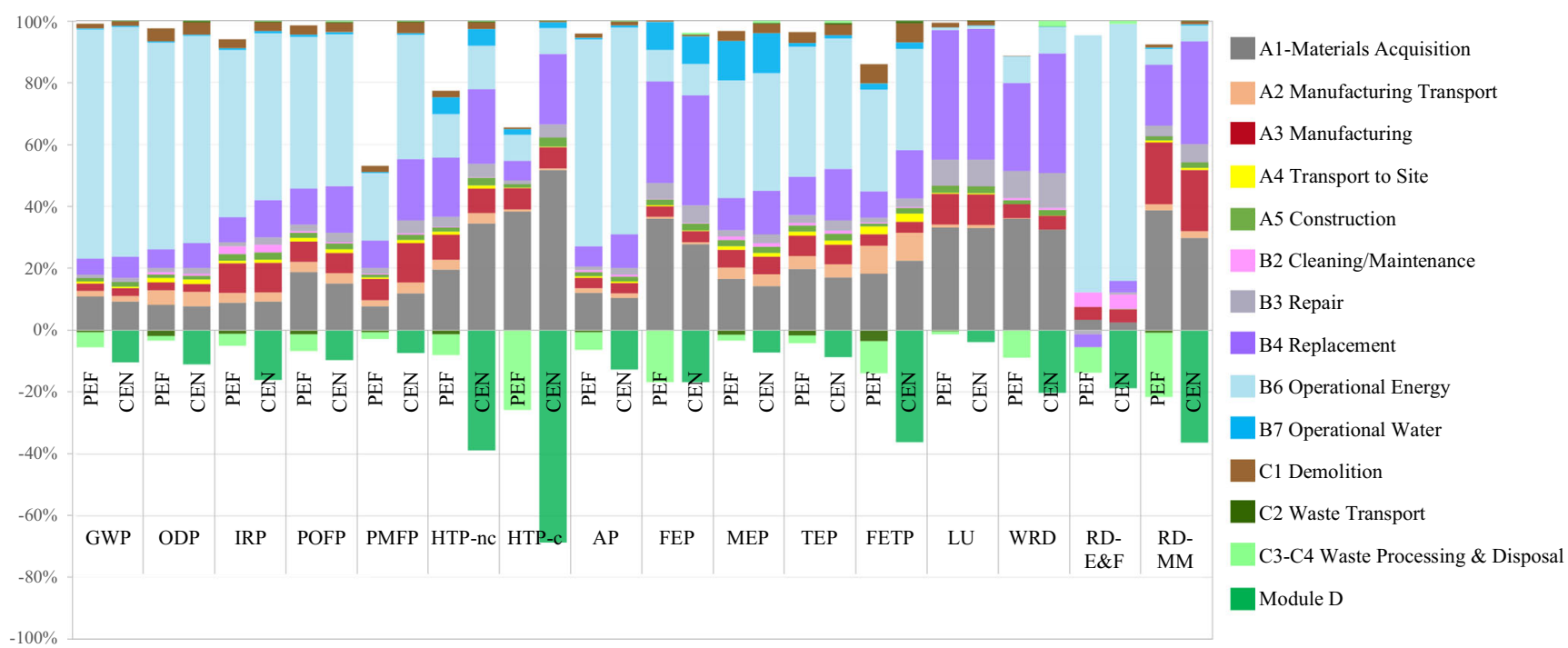

Fig. 2 Lyell building: relative comparison of characterized life cycle impacts, according to the PEF method and CEN standards

Figure 3 shows the life cycle normalized and weighted impacts. The overall normalized and weighted environmental impact of the Lyell building, excluding the toxicity indicators, over its 60 -year service life, equals 0.175 and 0.170 [points/ $\mathrm{m}^{2}$ ], according to PEF and CEN, respectively. This means that there is only $3.1 \%$ discrepancy between the two methods in the total impacts. If module $\mathrm{D}$ is not considered (cradle to grave), CEN result is 0.193 [points $/ \mathrm{m}^{2}$ ], i.e. $9.3 \%$ higher impacts than the PEF method. The $3.1 \%$ discrepancy is because of the different PEF allocation factors, namely " $\mathrm{A}$ " and "B". If toxicity indicators are included, these percentages increase to 5.7 and $21.1 \%$, when module D is included and ignored, respectively.

The Lyell building emits $3520\left[\mathrm{kgCO}_{2 \mathrm{eq}} / \mathrm{m}^{2}\right]$ when the PEF modelling approach with the CFF formula is applied. When the CEN approach with the formula presented in
Table 2 is used, Lyell's GWP equals $3378\left[\mathrm{kgCO}_{2} \mathrm{eq} / \mathrm{m}^{2}\right]$. Module D positively contributed $390\left[\mathrm{kgCO}_{2} \mathrm{eq} / \mathrm{m}^{2}\right]$. As Fig. 3 shows, GWP is by far the highest environmental issue caused by the Lyell building, which apart from the high weighting factor of the GWP indicator (21\%) is largely due to the high annual operational energy use (module B6). Accordingly, the environmental indicators that are largely influenced by module B6 show comparable results in both LCA methods as the modelling is identical (no allocation in this module). These include climate change (GWP), ozone depletion (ODP), ionizing radiation (IRP), photochemical ozone formation (POFP), acidification (AP) and resource use energy carriers (RD-E\&F). As the operational energy use of new low energy buildings is being drastically reduced, the impacts in module B6 of buildings are decreasing, and hence, the other life cycle stages are becoming relatively more important. For

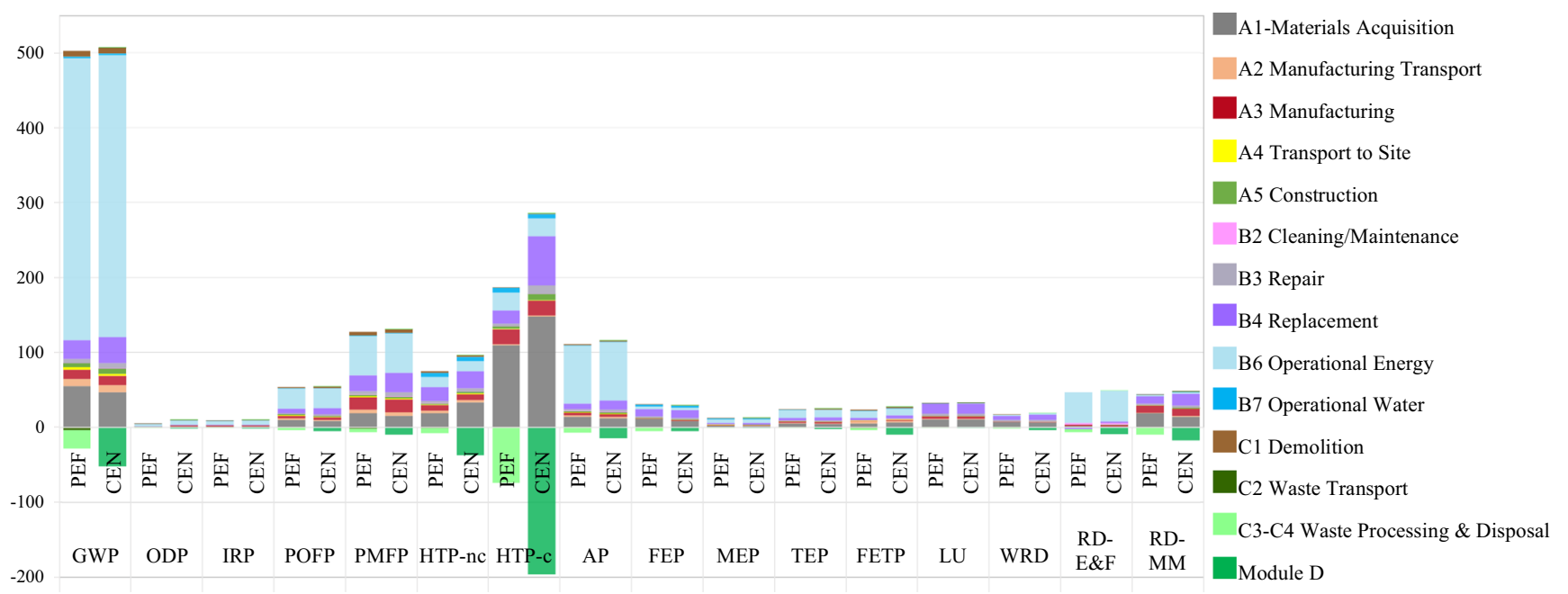

Fig. 3 Lyell building normalized and weighted life cycle impacts according to the PEF method and CEN standard 
these low energy buildings, a higher discrepancy between both methods is hence expected. To investigate this in more detail, the subsequent section focuses on the life cycle embodied impacts of the Lyell building.

The environmental hotspots, including the most relevant environmental impact categories and life cycle stages, are identified and are presented in Appendix E of the Supplementary Information. Both the CEN and PEF methods identified the same environmental indicators as hotspots, with a very similar share of each of these in the total impact. The difference between the contribution of some of the indicators is less than $0.5 \%$. For enhanced transparency, the authors hence recommend considering a minimum difference (i.e. $1 \%$ ) between hotspots at the $80 \%$ threshold as an additional rule. Considering this rule in this case study, both methods reveal the same most relevant environmental indicators.

The most relevant life cycle modules are identified for every most relevant environmental indicator (Supplementary Information, Table Appendix E-2). The PEF and CEN method identify the same most relevant life cycle modules, except for module D in CEN which replaces the C3-C4 Waste Processing and Disposal module in PEF. The contribution of life cycle stages is presented for the two LCA modelling approaches in Fig. 4 expressed as a single score. The results confirms the dominance of the operational energy use (B6) in buildings that are not low or nearly-zero energy buildings (NZEB) (Schwartz et al. 2018; Röck et al. 2020). The analysis furthermore shows a higher relative contribution of the operational energy use in the PEF approach compared with CEN, while the EoL stage has a higher significance according to the CEN approach.

The assessment shows that module $\mathrm{D}$ in the CEN results and module $\mathrm{C} 3-\mathrm{C} 4$ in $\mathrm{PEF}$ have a high positive contribution to the life cycle impact of the Lyell building thanks to the avoided impacts due to reuse, recycling, and energy recovery at EoL. This demonstrates the importance of a more accurate modelling of EoL treatment of construction materials and buildings in LCA studies. Although the quantification and inclusion of module D was optional in the EN 15804+A1 approach (CEN 2013), the second amendment of the standard (CEN 2019) mandates its reporting unless the conditions for exclusion are met. This paper confirms the importance of reporting module $\mathrm{D}$ to recognize and encourage reuse, recycling, and energy recovery, and hence a wider adoption of circular economy concepts in the construction industry.

\subsubsection{Life cycle embodied impacts at the building level}

Life cycle embodied impacts are defined as all impacts except those arising from operational energy and water use (B6 and B7). The life cycle embodied impacts comprise initial, recurring, and decommissioning impacts. Initial embodied impacts relate to the construction of the building, while recurring embodied impacts relate to the building materials used for replacements, repair, and maintenance over the building service life. Decommissioning embodied impacts relate to the building EoL (Ruochen and Abdol Chini 2017). The life cycle embodied impact of the Lyell building, excluding the toxicity indicators, equals 0.061 and 0.056 [points $/ \mathrm{m}^{2}$ ], according to PEF and CEN respectively, which shows $8.5 \%$ discrepancy between the two methods in the total single score impacts. This is only true when module $\mathrm{D}$ is considered. Without module D, CEN leads to $22.5 \%$ higher embodied impacts than PEF. Only considering the embodied GWP this discrepancy rises to $20 \%$, i.e. 712 and $570\left[\mathrm{kgCO}_{2} \mathrm{eq} / \mathrm{m}^{2}\right]$ as per the PEF and CEN approaches, respectively. This highlights the influence of the differences in EoL allocation of both methods in the life cycle embodied impacts of buildings. Identical
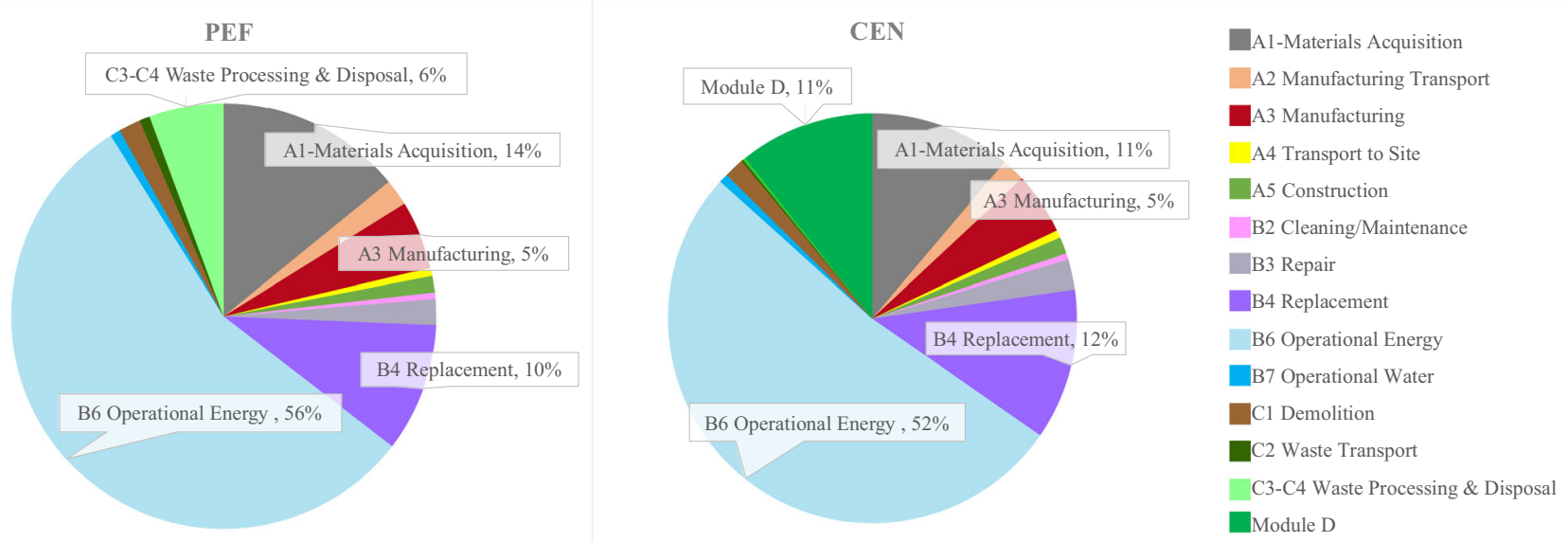

Fig. 4 Lyell building — relative contribution of life cycle modules to the single score impact, according to the PEF method and CEN standard 
relevant environmental impact categories were identified using the two methods (GWP, PMFP, RD-MM, AP, LU) with a similar share of life cycle embodied impacts (Supplementary Information, Table Appendix E-1).

The relation between embodied and operational emissions of buildings is currently however shifting as new buildings are low energy or NZEB. For these efficient buildings, emissions associated with materials manufacturing and processing are increasing in relative and absolute terms (Crawford et al. 2016; Röck et al. 2020). It is hence important to analyse the differences in embodied impacts for both methods in more detail, with a special focus on recycling and reuse strategies. An analysis at element and material level has therefore been performed.

\subsubsection{Life cycle embodied impacts at building element and material level}

The contribution of the various building elements and materials to the overall embodied building impact is analysed more in-depth to identify the strengths of both methods in assessing circularity and the main drivers of the environmental impact. The impact per building element and per material is presented in Fig. 5. The comparison shows that according to both the PEF and CEN methods, the highest impacts are caused by interior elements followed by building services. Furthermore, the highest discrepancy between both methods is noticed in the structural elements (super- and sub- structure). The main difference arises in the impact of in-situ concrete, reinforcing and sectional steel. Figure 6 shows a similar comparison but for each environmental indicator separately, highlighting that the main differences in normalized and weighted impacts between both methods occur in the GWP, HTP-c, HTP-nc, and RD-MM indicators.

Comparison of in-situ concrete with different avoided impact assumptions due to recycling at EoL According to the project specifications, the in-situ concrete is $\mathrm{C} 32 / 40$ with $20 \%$ cement replacement and no other recycled content. The RICS guide states that in the UK $90 \%$ of construction waste is recycled (RICS 2017). The following $R$ values are hence assumed: $R_{1}=0$ (recycled content), $R_{2}=0.9$ (recycling at EoL), $R_{3}=0$ (incineration with energy recovery). As there is no recycled content, the impact of the production stage ( $A 1$ to $A 3)$ is identical for the CEN and PEF methods. According to the PEFCR Guidance document v6.3, the end-of-life burdens and benefits due to recycling, reuse and energy recovery of concrete should be allocated with a factor of 0.5 (parameter $A$ in the CFF formula) to the previous and subsequent product. Accordingly, the PEF EoL scenario allocates half of the burdens and benefits of recycling and avoided virgin material to this product life cycle, while these are fully accounted for in module D in the CEN standard. The quality of recovered material and virgin material plays an important role in estimating the credits due to avoided use of virgin materials $\left(E^{*}{ }_{\mathrm{v}}\right)$. Thus, three scenarios for calculating the avoided impacts due to recycling are considered.

1. The first scenario assumes that the crushed concrete at EoL has the same quality as new concrete made from virgin materials $\left(E_{\mathrm{v}}=E_{\mathrm{v}}^{*}\right.$ and $\mathrm{Q}_{\mathrm{S}}$, out $\left./ \mathrm{Q}_{\mathrm{P}}=1\right)$.

2. In practice, crushed concrete has a limited use, i.e. as an aggregate for backfilling, which can replace virgin aggregates partially and must be considered as a lower quality product ( $E_{\mathrm{v}}^{*}$ of virgin aggregates). Therefore, the second
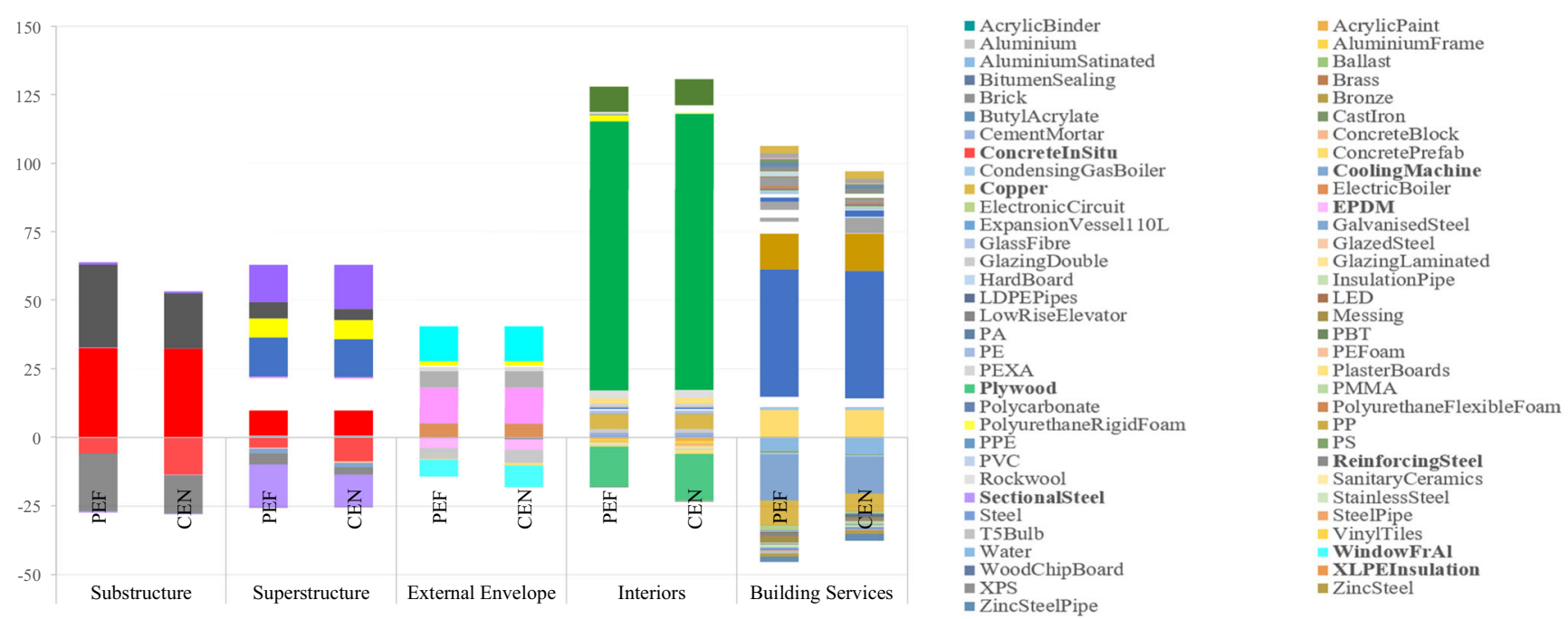

Fig. 5 Lyell building normalized and weighted life cycle embodied impact: contribution of building elements and materials, according to the PEF method and CEN standard 


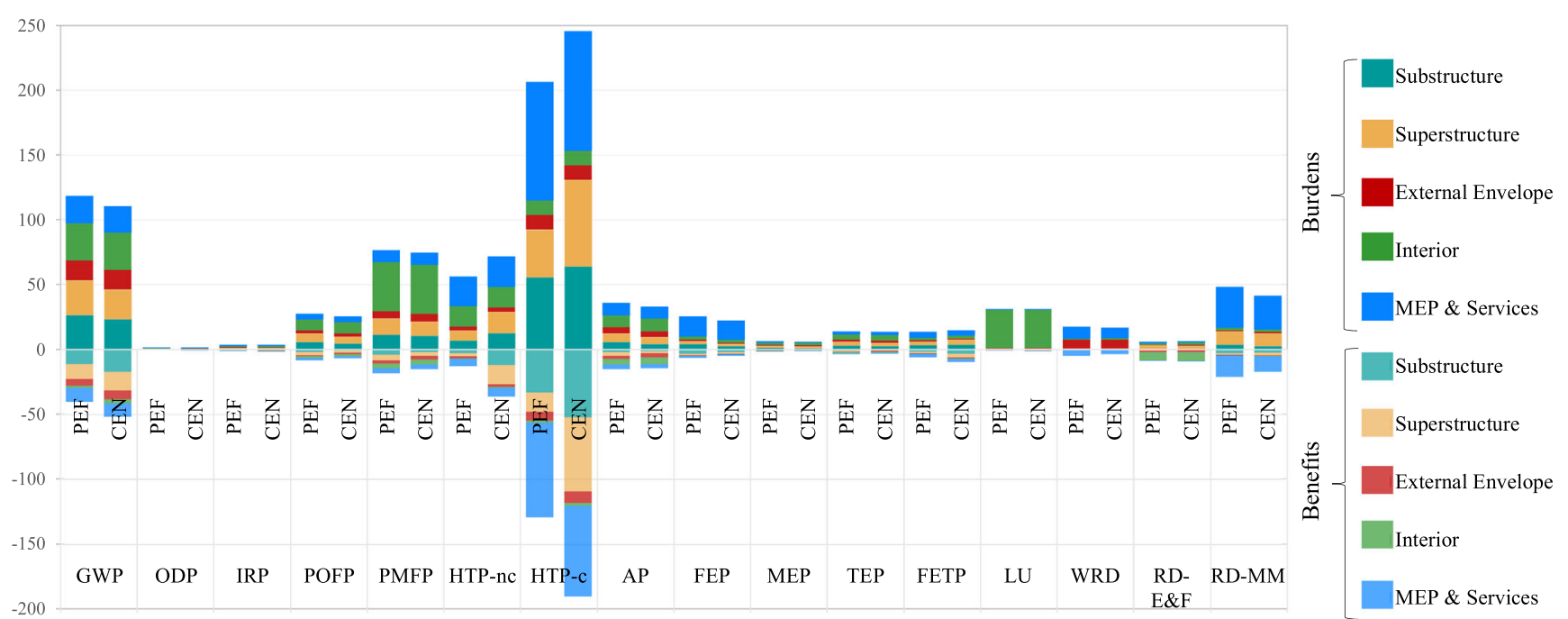

Fig. 6 Lyell building normalized and weighted life cycle embodied impact: contribution of the elements per impact category, according to the PEF method and CEN standard

scenario assumes that the quality of outgoing crushed concrete at the point of substitution $\left(Q_{\mathrm{s}, \text { out }}\right)$ equals $20 \%$ of the quality of primary or virgin concrete $\left(Q_{\mathrm{p}}\right)$.

3. The third scenario assumes that crushed concrete can be interchangeably used instead of virgin crushed gravel. This scenario can be considered as the closest to the actual use of crushed concrete.

Considering the first scenario, for most environmental indicators (e.g. GWP), the difference in EoL allocation factors results in lower benefits in PEF compared with CEN, i.e. less than half of the benefits (Fig. 7). Therefore, the single score according to PEF (0.0156) is $30 \%$ higher than CEN (0.0109) (excluding the toxicity indicators). In the second scenario, the burdens of the energy-intensive recycling process of concrete dominate the impacts. The CEN method shows an $18 \%$ higher single score than PEF, i.e. 0.0257 compared with 0.0210 . In the final scenario, which is the closest to the reality of the market value of crushed concrete, the PEF method again shows a higher total single score impact (0.0188) than the CEN approach (0.0177), but the difference is limited to $6 \%$.

These three scenarios demonstrated the capability of the PEF and CEN methods in offering transparency and insight into the EoL results and showed that both methods lead to the same decision taking for the three concrete scenarios. As the PEF method more distinctively captures the burdens and benefits due to avoided transportation and virgin material manufacturing, it offers a better understanding of causes of the burdens and benefits.

The case of reinforcing steel Reinforcing steel in the Lyell building is assumed to have 54\% recycled content (as per
Annex C of the PEFCR Guidance v6.3 (EC 2017a)), and at the EoL $96 \%$ is assumed to be recycled and $4 \%$ landfilled (RICS 2017) $\left(R_{1}=0.54, R_{2}=0.96, R_{3}=0\right)$. The RICS guide recommends $97 \%$ recycled content for reinforcement steel bars as the default specification in the UK (RICS 2017); therefore, for sensitivity analysis, $R_{1}=0.97$ is considered in the assessment (second scenario). Because the use of recycled steel is widespread, only $20 \%$ of the benefits of recycled steel is awarded to the user in the PEF approach $(A=0.2)$. The PEF method hence leads to higher impacts in module A1 than the CEN approach, shown in Fig. 8. At the EoL, $80 \%$ of the recycled steel and the equivalent primary steel that is salvaged are considered. In the CEN approach, the recycled content is reduced from the recycling ratio at the EoL to calculate the amount of primary steel that will be salvaged ( $R_{1}-R_{2} \mathrm{~kg}$ avoided primary steel). Therefore, PEF measures higher benefits at the EoL due to avoided use of virgin steel, but these are not enough to compensate for the product stage (Fig. 8). This results in a life cycle embodied impact of $5.90 \times 10^{-5}$ and $4.00 \times 10^{-5}$ for PEF and CEN, respectively. The second scenario $\left(R_{1}=0.97\right)$ shows lower discrepancy between the results as per the two methods, i.e. $4.63 \times 10^{-5}$ and $4.00 \times 10^{-5}$ per $\mathrm{kg}$ steel according to $\mathrm{PEF}$ and CEN, respectively. The comparison of the scenarios moreover shows that increasing the recycled content of steel does not change the life cycle embodied impact according to CEN (if $R_{2}>R_{1}$ ), while according to PEF this does lead to a reduced impact. Hence, the PEF method better supports circular building strategies.

Appendix F of the Supplementary Information presents the amount of the input/output flows for in-situ concrete and reinforcing steel used in the calculations. 


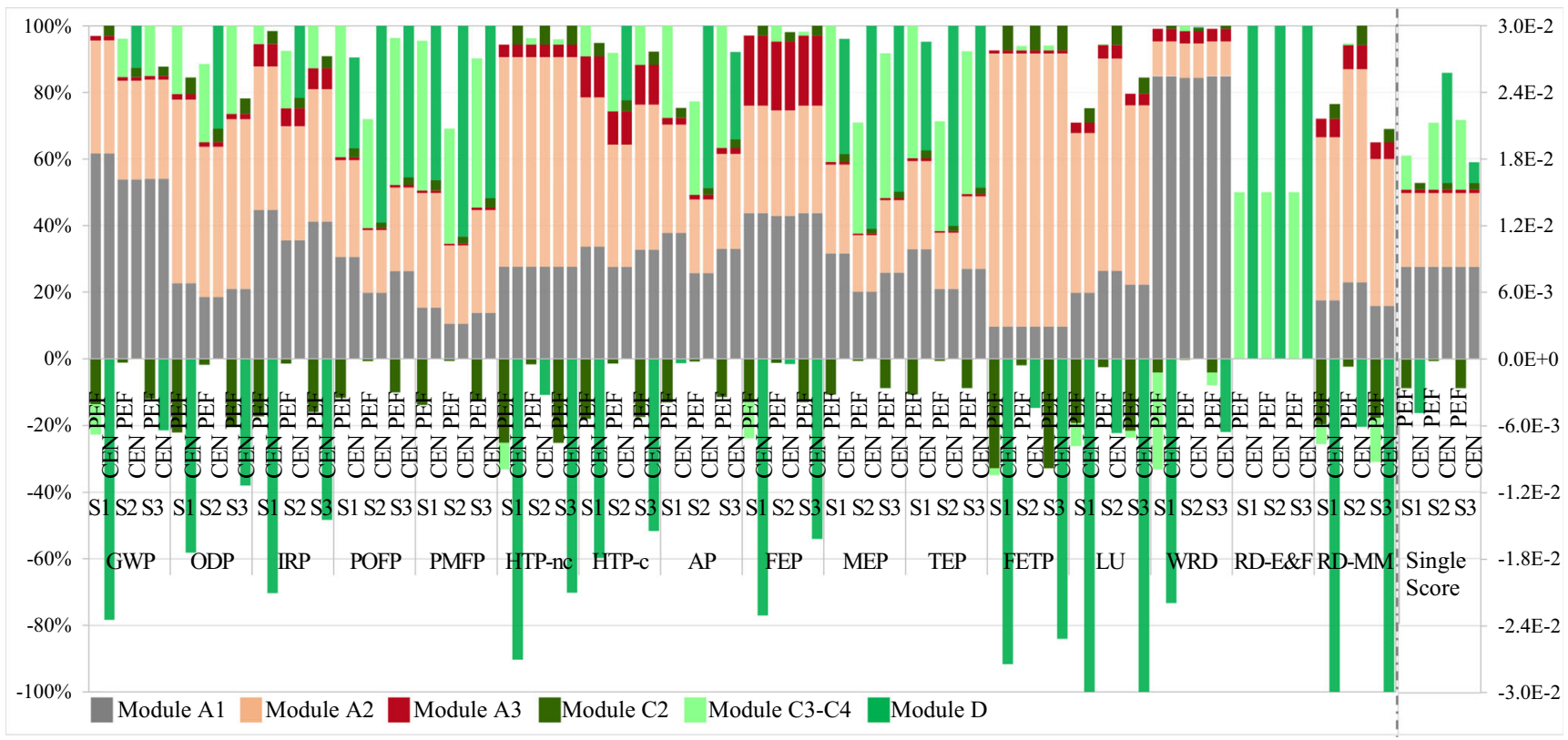

Fig. 7 Relative comparison of characterized life cycle embodied impact (left axis) and single score (excluding toxicity indicators-right axis) of $1 \mathrm{~m}^{3}$ of in-situ concrete, according to the PEF method and CEN standard, considering three scenarios for calculating the avoided impacts due to recycling at EoL

\section{Discussion and recommendations}

Various insights have been gained based on the comparative assessment of the Lyell building with the PEF method and CEN standards (EN 15804+A1 and EN 15978). The following section summarizes the main learnings from the comparison of the methods on the issues addressed in this paper. By the time this research was concluded, the second amendment of the EN 15804 standard was published. Although the CEN modelling was performed as per EN 15804+A1, the effects of these revisions on the results are included in the subsequent paragraphs.

\subsection{Life cycle environmental impact}

The analysis showed that the differences in EoL allocation between the PEF and CEN methods do not result in large differences in life cycle impact of the Lyell building. The small difference is however due to the dominance of the

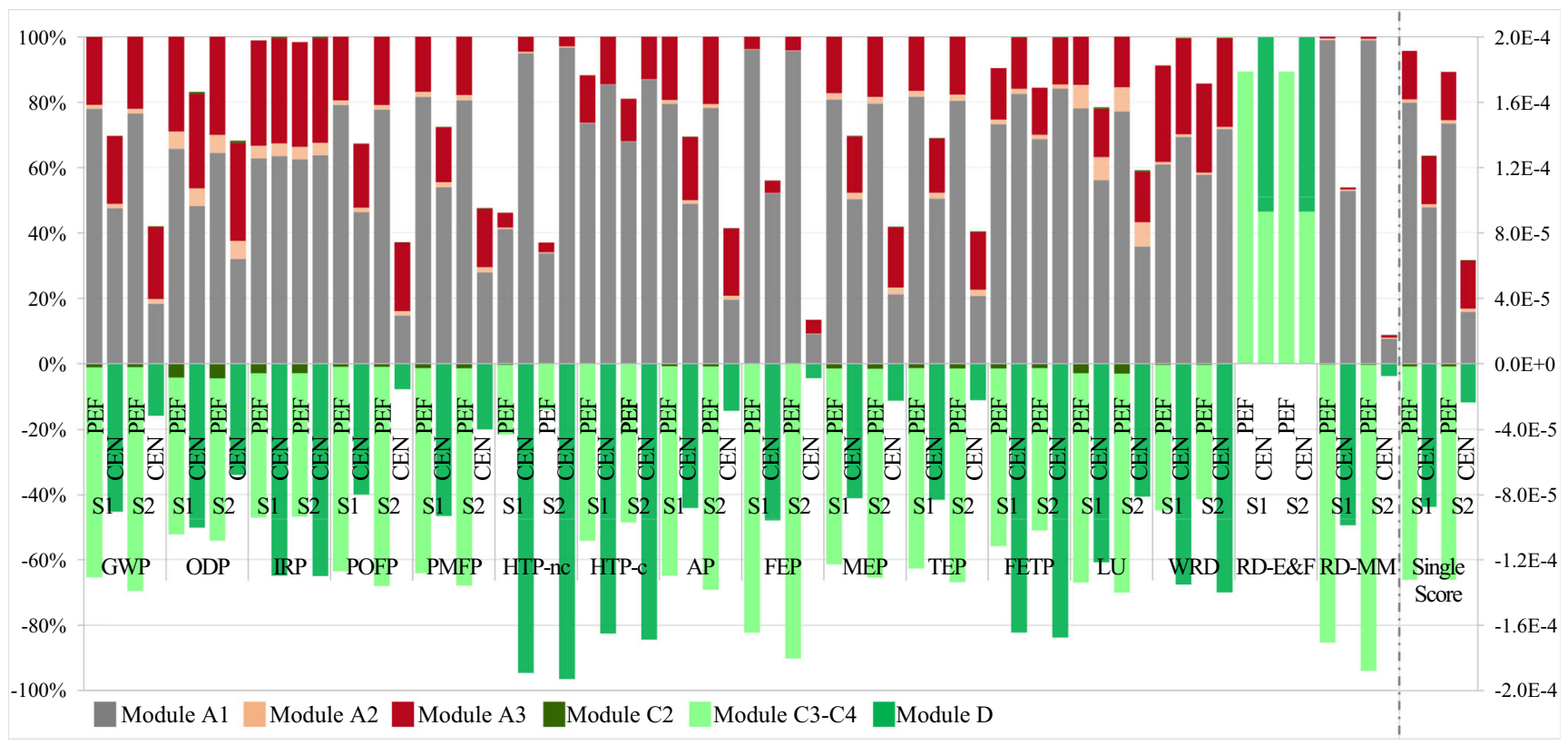

Fig. 8 Relative comparison of characterized life cycle embodied impact (left axis) and single score (excluding toxicity indicators - right axis) of $1 \mathrm{~kg}$ of reinforcing steel, according to the PEF method and CEN standard, considering two scenarios for recycled content 
operational energy use of the building which is identically modelled in both methods. The embodied impacts show larger differences, i.e. $8.5 \%$ for the single score and $20 \%$ for global warming. As the share of operational energy use in the life cycle environmental impact of buildings is decreasing and hence the share of product and EoL stages increases (Crawford et al. 2016; Röck et al. 2020), harmonization of the two LCA methods gains importance. This is confirmed by the higher differences in results between both methods at element and material level.

The environmental impact categories of the EF method 2.0 were used in this paper for both the PEF and CEN modelling (as described in Section 3.1.3). The EN 15804+A2 defines the (core and additional) environmental indicators and units, characterization factors as the EF Reference Package 3.0 (EF v3.0) (CEN 2019; EC 2020) which are identical to these of EF v2. Modelling according to EN 15804+A2 would hence not lead to differences in results based on impact categories/indicators.

\subsection{End of life modelling}

The PEF CFF formula terms were translated as per the EN 15804+A1 standard rules (Table 2) to allow for comparison of the application of the PEF method and CEN standards in practice. Each approach has its benefits and drawbacks in modelling the end-of-life allocation and offering more insights contributing towards achieving circular economy targets.

Firstly, the PEF method uses the CFF formula to report the environmental burdens and credits between consecutive systems reflecting market realities at the product and EoL stages, while the CEN standards use the "cut-off" approach and collectively report the material and energy recovery credits in module D beyond the product system boundary. Declaring the EoL impacts using the CFF formula reflects the market realities related to circularity, particularly when the allocation and quality factors are considered. The reporting of the sum of the burdens and avoided impacts in each module however leads to a lower level of transparency as burdens and benefits cancel each other out. For instance, in this case-study, the benefits of the recovery of material losses during the construction process, waste produced for repairing building elements, and building components discarded due to replacement at the EoL, are reported in modules A5, B3 and B4 respectively, and discounted the burdens. To increase transparency, it is recommended to report burdens and benefits per life cycle stage separately, instead of adding these up and limiting the reporting to the net burdens (or benefits, if the latter is larger than the burdens). The CEN approach declares the aggregate of all the avoided impacts separately in module $\mathrm{D}$, beyond the product system boundary. Although this approach succeeds in transparent reporting of the burdens and benefits separately, it compromises insights about the source of benefits by not reflecting the life cycle module with the material or energy recovery opportunity and collectively reporting these in module D. It is hence recommended to increase transparency by requiring to report the benefits per life cycle module in module D. This could, for example, be done under different names such as Module $\mathrm{D}_{\mathrm{A} 1}$ to Module $\mathrm{D}_{\mathrm{C} 4}$. Increasing the transparency of burdens versus benefits (opportunities for avoided impacts) and when these occur in the life cycle of the building will better support designers and LCA practitioners in identifying opportunities for improving the building and reducing the environmental impact.

Secondly, the significant contribution of recycling and recovery activities at EoL (at the point of substitution or after end-of-waste state has reached), which are reported in modules D in CEN and C3-C4 in PEF, reveals the importance of rigorous and binding reporting of these activities in the realization of circular economy principles in the construction industry. The results of the various sensitivity analyses of concrete moreover demonstrate that the "allocation" and "quality" factors considered in the CFF play a key role in offering more realistic projections of life cycle impacts. For instance, when calculating the credits due to avoided use of virgin materials $\left(E_{\mathrm{v}}^{*}\right)$ the quality of recovered material and virgin material plays an important role.

Thirdly, the CEN approach based on the efficiency of energy recovery of materials determines whether the impacts belong to module $\mathrm{C} 3$ or $\mathrm{C} 4$. In this study, $\mathrm{C} 3$ and $\mathrm{C} 4$ were collectively reported as per the PEF approach and did not impact the reporting and interpretation of the results and therefore for simplification purposes the jointly reporting approach of energy recovery processes is recommended for these two modules.

Finally, EN 15804+A2 (CEN 2019) offers an (informative) EoL formula that is similar to the proposed formula in this work, but it uses different terms to differentiate between materials and fuels. There are two important differences in the EoL formula in EN15804+A2 and the one proposed in this paper. Firstly, the EN15804+A2 formula assumes that $E_{\text {recycling }}$ equals $E_{\text {recycled }}$ and that $E_{\mathrm{v}}$ equals $E^{*}{ }_{\mathrm{v}}$. This means that the formula works well for closed-loop recycling but leads to wrong results for open-loop recycling (i.e. in the cases where recycling at EoL is a different process than the recycled content). The EoL formula proposed in this paper applies to both closed-loop and open-loop recycling. Secondly, the EN 15804+A2 formula reports all impacts at each life cycle stage collectively (stages A, C), while the formula proposed in this paper differentiates between all modules. The latter (modular) approach improves the understanding of the drivers of the life cycle environmental impacts and potential benefits.

\subsection{Life cycle inventory}

Various challenges were encountered in generating the required LCI data. These are discussed in this section to 
clarify the shortcomings of current databases as these are essential for assessing the life cycle impacts of buildings and circular building strategies.

At product level, the modular approach of the CEN standards requires the life cycle inventory data to be collected accordingly. Widely used databases, such as the Ecoinvent and $\mathrm{GaBi}$, do not fully support this. The datasets do not always differentiate the life cycle modules A1 to A3 and merge these modules. These datasets hence require a refactoring to be used for modelling the PEF CFF formula. At times, this remodelling process is not straightforward as it is not always clear in these datasets which (share of the) input/output flows belong to module $\mathrm{A} 1, \mathrm{~A} 2$ or $\mathrm{A} 3$. The manual remodelling of the Ecoinvent datasets for the assessment in this paper proved time-consuming and restricted. Accordingly, the authors recommend a separate reporting of the A1 to A3 modules in generic databases and in the communication of LCA results.

The relatively long building service life and ambiguous nature of the downstream processes (deconstruction, transportation and disposal) make EoL modelling inherently uncertain. This uncertainty requires the LCA practitioner to define EoL scenarios for each material in the building, which is timeconsuming. Default national EoL scenarios and assumptions are hence recommended to assist the EoL modelling, increase consistency between studies and reduce time efforts in the LCA modelling. In addition, little or no information is available in generic databases regarding the recycling processes of construction products. The authors hence recommend that both the construction sector and the LCI database developers put efforts in providing this lacking information regarding recovery and recycling processes of construction products and indicate the products that can use others as a secondary material at their EoL. The influence of accurate assumptions regarding the avoided virgin material was demonstrated in this study in the case of concrete.

The following two types of data gaps are common in LCA studies: (1) lack of product system information and (2) lack of input/output flows of the products and/or processes. When assessing a building, the first type of data gap can either be due to incomplete information about the building and its composition or unavailability of information related to life cycle stages such as construction or EoL. The second data gap is the lack of environmental information of construction products or processes (i.e. lacking EPDs or no information in generic LCI databases). In this study, it was mainly the second type of data gap that occurred. An extensive number of building documents was available to the research team, including a BIM model. A thorough bill of materials was developed for all building elements, materials, and processes. The translation of this comprehensive bill of materials to environmental impacts using the Ecoinvent database, however, required major simplifications of data to general material and product data rather than as per project specifications. The modelling of building services was affected the most. The HVAC systems were modelled as the sum of the quantities of main materials of a selective number of components in the system because there was not enough information available about the exact process or product in the Ecoinvent database. The authors hence encourage the sector in providing EPDs of their products and the database developers to broaden the scope of their database with these HVAC systems.

\section{Conclusions}

The environmental impact of the built environment needs to be reduced substantially and life cycle assessment (LCA) is an internationally accepted methodology to assist this aim. In this study, the two prominent LCA methods in Europe, the EC PEF method and the CEN standards EN 15804+A1 and EN15978 were compared with a focus on the end-of-life modelling and allocation approach. An end-of-life formula for the CEN standards is proposed in this paper in response to the issue of variation in interpretation of the standards. Both the EC PEF method and CEN standards were used to assess the environmental impact of a newly constructed office building, which showed similar life cycle impact results. The embodied life cycle impacts differed to a greater extent and hence a further alignment of both methods is recommended, especially for Nearly Zero Energy Buildings with larger importance of embodied impacts.

This work assists LCA practitioners in comparing the difference in the impact of construction products and buildings, usually calculated as per EN 15804, with an assessment according to the PEF method. The comparative analysis revealed that the PEF method allows to show how increasing recycled content reduces life cycle impacts and how recycling at EoL at high quality level is preferred over downcycling. While the latter is also reflected by the EN 15804, the former is not well reflected in the CEN standard due to its "net benefit" approach. It can hence be concluded that the PEF "allocation" and "quality" factors offer more realistic projections of recycled content and EoL impacts. Nevertheless, the assessment revealed that the results of the EC PEF method are less transparent than the ones of the CEN standards as the EC PEF method adds up burdens and benefits per life cycle stage. Also, the transparency of the results of the CEN standards can be improved by requiring to report the benefits in module D per life cycle stage, rather than a single number. In order to increase comparability, credibility and robustness of LCA results, this study recommends more prescriptive guidelines. In addition, a further harmonization between the EC PEF method and the CEN standards and a higher level of detail in end-oflife reporting is recommended.

Various methodological challenges were identified when implementing the methods. The main ones are the lack of 
databases that are compatible with the end-of-life modelling requirements of both methods. This incompatibility required remodelling of the end-of-life datasets and was time consuming and can be inconsistent across modellers. Besides the incompatibility, the databases moreover showed important shortages for certain building components, with two important ones being the mechanical and electrical systems, and recycling processes. It is hence recommended that both the construction sector and the LCI database developers put efforts in providing this lacking information.

Acknowledgements The invaluable contribution and support of Dr. Gillian F. Menzies, Dr. Edward Owens, Ingrid Berkeley, Neil Cogan, Marisa Viera, Carolin Spirinckx, Lisa Damen, VITO NV, PRé Sustainability, and the Energy Technology Partnership Scotland funding are greatly appreciated.

Open Access This article is licensed under a Creative Commons Attribution 4.0 International License, which permits use, sharing, adaptation, distribution and reproduction in any medium or format, as long as you give appropriate credit to the original author(s) and the source, provide a link to the Creative Commons licence, and indicate if changes were made. The images or other third party material in this article are included in the article's Creative Commons licence, unless indicated otherwise in a credit line to the material. If material is not included in the article's Creative Commons licence and your intended use is not permitted by statutory regulation or exceeds the permitted use, you will need to obtain permission directly from the copyright holder. To view a copy of this licence, visit http://creativecommons.org/licenses/by/4.0/.

\section{References}

AFNOR Normalisation (2017) CEN TC 350 - standards overview http:// portailgroupe.afnor.fr/public_espacenormalisation/centc350/ standards_overview.html. Accessed 24 Sept 2018

Allacker K (2010) Sustainable building: the development of an evaluation method. Dissertation, KU Leuven

Allacker K et al. (2016) Which additional impact categories are ready for uptake in the CEN standards EN 15804 and EN 15978? Evaluation framework and intermediate results. Sustainable built environment (SBE) regional conference. Zurich, pp. 514-519. https://doi.org/10. 3218/3774-6_83

Bach V et al. (2018) Product environmental footprint (PEF) pilot phasecomparability over flexibility?, Sustainability. Multidisciplinary Digital Publishing Institute, 10(8), p. 2898. https://doi.org/10. 3390/su10082898

Del Borghi A, Moreschi L and Gallo M (2019) Communication through ecolabels: how discrepancies between the EU PEF and EPD schemes could affect outcome consistency, International Journal of Life Cycle Assessment. p. 1-16. https://doi.org/10.1007/s11367019-01609-7

BRE Global Ltd (2014) BREEAM new construction-non-domestic buildings-technical manual. https://www.breeam.com/ BREEAMUK2014SchemeDocument. Accessed 5 Apr 2017

BRE Group (2018) BRE global product category rules for type III environmental product declaration of construction products to EN 15804:2014+A1. http://www.bre.co.uk/filelibrary/Materials/BREEN-15804-PCR-PN514.rev-0.1.pdf. Accessed 7 Dec 2019
BRE Ltd (1996) BRE group: green guide to specification. http://www. bre.co.uk/greenguide/podpage.jsp?id=2126. Accessed 7 Dec 2015

CEN (2011) BS EN 15978:2011 — sustainability of construction works assessment of environmental performance of buildings - calculation method

CEN (2013) EN 15804:2012+A1:2013 sustainability of construction works - environmental product declarations - core rules for the product category of construction products

CEN (2019) EN 15804:2012+A2:2019 sustainability of construction works - environmental product declarations - core rules for the product category of construction products

Crawford RH, Bartak EL, Stephan A, Jensen CA (2016) Evaluating the life cycle energy benefits of energy efficiency regulations for buildings. Renew Sust Energ Rev 63:435-451. https://doi.org/10.1016/j. rser.2016.05.061

DEFRA (2018) UK statistics on waste. London. http://www. statisticsauthority.gov.uk/assessment/code-of-practice/index.html. Accessed 29 Apr 2018

Durão, V., Silvestre J. D., Mateus R., de Brito J. (2020) Assessment and communication of the environmental performance of construction products in Europe: comparison between PEF and EN 15804 compliant EPD schemes, resources, conservation and recycling. Elsevier, 156, p. 104703. https://doi.org/10.1016/J.RESCONREC. 2020.104703

EC (2013) Commission recommendation of 9 April 2013 on the use of common methods to measure and communicate the life cycle environmental performance of products and organisations, Off J Eur Union. Brussels. https://doi.org/10.3000/17252555.L_2010.276. eng

EC (2017a) PEFCR guidance v6.3

EC (2017b) Single market for green products - the product environmental footprint pilots - environment-European Commission. http:// ec.europa.eu/environment/eussd/smgp/ef_pilots.htm. Accessed 24 Sept 2018

EC (2018) Final conference of the environmental footprint - environment-European Commission, EC. http://ec.europa.eu/ environment/eussd/smgp/EFconference_2018.htm. Accessed 29 Jun 2018

EC (2020) Environmental Footprint reference packages - European Platform on Life Cycle Assessment, EC. https://eplca.jrc.ec. europa.eu/LCDN/developerEF.xhtml;jsessionid= BFE16F0758E99202BC484D10E0F82B04. Accessed 23 Jun 2020

EC-JRC-Institute for Environment and Sustainability (2010) International reference life cycle data system (ILCD) handbookgeneral guide for life cycle assessment-detailed guidance. Luxembourg. https://doi.org/10.2788/38479x. Accessed 24 Sept 2018

ecoinvent (2020) http://www.ecoinvent.org. Accessed 23 Jun 2020

EPD International (2018) Buildings - product category classification: UN CPC 531. https://www.environdec.com/PCR/Detail/?Pcr= 5950. Accessed 23 Jun 2020

Finkbeiner M (2014) Product environmental footprint— breakthrough or breakdown for policy implementation of life cycle assessment? Int J Life Cycle Assess 19(2):266-271. https://doi.org/10.1007/s11367013-0678-x

Galatola M, Pant R (2014) Reply to the editorial "Product environmental footprint - breakthrough or breakdown for policy implementation of life cycle assessment?" written by Prof. Finkbeiner. Int J Life Cycle Assess 19(6):1356-1360. https://doi.org/10.1007/s11367014-0740-3

Hunsager EA, Bach M, Breuer L (2014) An institutional analysis of EPD programs and a global PCR registry. Int J Life Cycle Assess 19(4): 786-795. https://doi.org/10.1007/s11367-014-0711-8

Ibáñez-Forés V, Pacheco-Blanco B, Capuz-Rizo SF, Bovea MD (2016) Environmental product declarations: exploring their evolution and 
the factors affecting their demand in Europe. J Clean Prod 116:157169. https://doi.org/10.1016/J.JCLEPRO.2015.12.078

ISO (2015) BS ISO 12006-2:2001—building construction —organization of information about construction works - part 2: framework for classification of information, ISO, http://www.iso.org/iso/iso catalogue/catalogue_tc/catalogue_detail.htm?csnumber $=38706$. Accessed 20 Jun 2020

Lasvaux S, Gantner J, Wittstock B, Bazzana M, Schiopu N, Saunders T, Gazulla C, Mundy JA, Sjöström C, Fullana-I-Palmer P, BarrowWilliams T, Braune A, Anderson J, Lenz K, Takacs Z, Hans J, Chevalier J (2014) Achieving consistency in life cycle assessment practice within the European construction sector: the role of the EeBGuide InfoHub. Int J Life Cycle Assess 19(11):1783-1793. https://doi.org/10.1007/s11367-014-0786-2

Minkov N, Schneider L, Lehmann A, Finkbeiner M (2015) Type III environmental declaration programmes and harmonization of product category rules: status quo and practical challenges. J Clean Prod 94:235-246. https://doi.org/10.1016/j.jclepro.2015.02.012

Passer A, Lasvaux S, Allacker K, de Lathauwer D, Spirinckx C, Wittstock B, Kellenberger D, Gschösser F, Wall J, Wallbaum H (2015) Environmental product declarations entering the building sector: critical reflections based on 5 to 10 years' experience in different European countries. Int J Life Cycle Assess 20(9):11991212. https://doi.org/10.1007/s11367-015-0926-3

RICS (2017) Whole life carbon assessment for the built environment, RICS professional statement. London. http://www.rics.org/uk/ knowledge/professional-guidance/professional-statements/wholelife-carbon-assessment-for-the-built-environment-1st-edition . Accessed 1 Aug 2018

Röck M et al (2020) Embodied GHG emissions of buildings - the hidden challenge for effective climate change mitigation. Appl Energy 258: 114107. https://doi.org/10.1016/J.APENERGY.2019.114107
Ruochen Z, Abdol Chini (2017) A review of research on embodied energy of buildings using bibliometric analysis. Energy Build 155: 172-184. https://doi.org/10.1016/J.ENBUILD.2017.09.025

Sala $S$ et al. (2017) Global normalisation factors for the environmental footprint and life cycle assessment. Luxembourg. https://doi.org/10. $2760 / 88930$

Schwartz Y, Raslan R, Mumovic D (2018) The life cycle carbon footprint of refurbished and new buildings - a systematic review of case studies. Renew Sust Energ Rev 81:231-241. https://doi.org/10.1016/J. RSER.2017.07.061

SimaPro UK Ltd (2020) http://www.simapro.co.uk. Accessed 23 Jun 2020

Technical Secretariat Decorative Paints (2018) PEFCR - decorative paints

Technical Secretariat of the PEF Thermal Insulation Pilot (2016) Draft PEFCR for thermal insulation version 4.2

Technical Secretariat PEF Pilot on Piping Systems (2016) Draft PEFCR for hot and cold-water supply piping systems in the building version 3.1

Thinkstep AG (2016) Draft PEFCR for metal sheets for various applications, revision $0.9 \mathrm{a}$

Trigaux D, Wijnants L, de Troyer F, Allacker K (2017) Life cycle assessment and life cycle costing of road infrastructure in residential neighbourhoods. Int J Life Cycle Assess 22(6):938-951. https:// doi.org/10.1007/s11367-016-1190-x

VITO, KU Leuven and TU Graz (2018) PEF4Buildings - study on the application of the PEF method and related guidance documents to a newly office building (ENV.B.1/ETU/2016/0052LV). https://doi. org/10.2779/23505

Publisher's note Springer Nature remains neutral with regard to jurisdictional claims in published maps and institutional affiliations. 